\title{
The Influence of Work Experience on Subjective Evaluation of Technologies: The Case of the Japanese Animation Industry
}

\author{
Takeyasu Ichikohji \\ Toyo University
}

*Corresponding Author: Takeyasu Ichikohji, Toyo University

\begin{abstract}
Researchers have often examined the roles of capability and cognition within organizations experiencing technological changes. We focus on employee cognition, which affects both capability and cognition within organizations. The evaluation of new technologies is an important factor for introducing these technologies in an organization. To verify whether work experiences influence the evaluation of technologies, we introduce a new concept named subjective evaluations of technological life cycles (TLCS) and conduct a survey. The survey is designed to evaluate five animation technologies (freehand drawing, 3DCG, hybrid, Flash, and stereovision), two markets (theaters and television), and two participant types (animators and vocational college students). We plot these technologies on two evaluative axes of "future potential" and "present status" based on TLCS to analyze the relationships between technologies within the Japanese animation industry, using data that includes 140 animators and 291 vocational college students learning animation. The results indicate that the experience of working in the industry negatively affected cognition of the future potential of existing technologies and the present status of promising new technologies. However, it did not affect the future potential of promising new technologies and the present status of existing technologies.
\end{abstract}

Keywords: Work experience, Subjective evaluation, Process technologies, Product Life Cycle, Japanese animation

\section{INTRODUCTION}

Company growth is primarily dependent on the resources that a company possesses ${ }^{[1]}$. Related to this, Prahalad and Hamel asserted that relative to American companies, Japanese companies better understand and cultivate such resources ${ }^{[2]}$. However, Prahalad and Hamel's assertion was made more than 25 years ago. Following the 1990s, Japan's economy experienced a significant downturn during a period colloquially called the Lost Two Decades. Even if macroeconomic forces kept most Japanese companies afloat, these companies were nonetheless forced to rethink the manner in which they cultivated and utilized their resources. After all, a company's present success does not mean its future success. It is difficult for companies to prepare for the future.

Many researchers have indicated that a company's past experiences have an influence on its future ${ }^{[3][4][5]}$. These influences are not always positive. For instance, a company's core capabilitieswhich can be deeply rooted in that organization's values - can inhibit innovation ${ }^{[3]}$. To ensure continuous innovation, organizations must adapt. Research on adaptation has primarily adopted one of two perspectives: the role of cognition and capabilities. With respect to the former, some researchers have emphasized management cognitions in response to environmental change; the latter line of research has emphasized the role of asset reconfigurations ${ }^{[6]}$.

Cognitive theory dictates that reality is selectively perceived, cognitively rearranged, and interpersonally negotiated. As such, technology can be better understood through cognitive variables and decision premises than through behavior ${ }^{[7]}$. A cognitive approach to understanding technology would suggest that the concept of "technology" resides at the intersection of the mental and physical

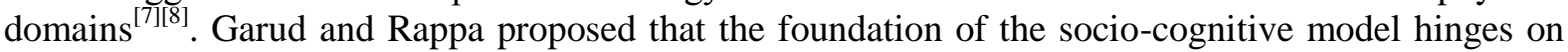
three basic definitions of technology: technology as beliefs, technology as artifacts, and technology as evaluation routines ${ }^{[9]}$. Reciprocal interactions between these three definitions give rise to cognitive processes. Cognitions among management personnel affect organizational decision-making [10][11][12] [13][14][15][16][17]. Rosenbloom argued that falling profits for NCR (an information systems company in 
the 1970s) were largely due to managerial mental structures that were averse to innovation and adaptation $^{[16]}$. Similarly, when typewriter usage declined, the Smith-Corona company failed because its managers had incorrect cognitions about their resources and ability (or lack thereof) to enter into other industrial sectors ${ }^{[1]}$. Related to these two examples, Helfat and Peteraf introduced the words "managerial cognitive capability," which highlights the fact that managerial capabilities are not limited to the capacity to perform physical activities, but to engage in effective mental activities as well ${ }^{[14]}$.

Generally speaking, there are two key theoretical perspectives related to organizational capabilities. The first is innovation theory ${ }^{[18][19][20][21][22][23]}$. Past research has shown that organizations that adhere to technologies on which they were founded are unable to effectively adapt to technical changes in the business environment or among their competitors. Innovation theory dictates that competencedestroying technical shifts demand that organizations develop new skills, cultivate novel abilities, and develop new knowledge ${ }^{[23]}$. A second perspective relates to "dynamic capabilities" among organizations ${ }^{[24][25][26][27]}$. Work based on this perspective has largely focused the role of the manager in reconfiguring assets to cope with environmental shifts ${ }^{[24][28]}$. In a quantitative analysis of the American petroleum industry, Adner and Helfat found that managerial decisions in response to environmental changes significantly affected several business-related outcomes ${ }^{[28]}$. Their analysis was not performed in isolation; many other researchers have also investigated the relationship between managerial decision-making and company performance ${ }^{[29][30][31][32][33]}$.

Because researchers of cognition and capabilities have historically focused on different issues, there are few studies on the relationship between the two concepts ${ }^{[34]}$. In recent years, however, some scholars have explored this association ${ }^{[6][12][34][35]}$. Kaplan (2008) demonstrated that both cognition and capabilities respectively shape organizational outcomes; the author also found that effective cognition can compensate for a lack of organizational capabilities ${ }^{[35]}$. Laamanen and Wallin found that the effects of managerial cognition can be detected at three distinct levels of capability development: operational capabilities level, firm's capability portfolio level, and extended enterprise level ${ }^{[34]}$. In contrast to these studies, Vergne and Depeyre argued that neither dynamic capabilities nor superior cognition are necessary for organizational adaptation to technological changes. Given these empirical inconsistencies, it is difficult to offer definitive conclusions about cognitions and capabilities from the extant literature ${ }^{[6]}$. To help clarify the relationship, this study evaluates employees' technologyrelevant cognitions and their respective effects on managerial cognitions and organizational capabilities.

\section{THEORETICAL FRAMEWORK}

Top managers often make judgments based on their experiences with employees, and employee cognitions influence how managers reconfigure assets as well. Initial research on cognitions related to new technologies began in the mid-1970s, and focused largely on information technology in management information science and industrial marketing. Specifically, Davis, Bagozzi, and Warshaw elaborated on Fishbein and Azjen's Theory of Reasoned Action (TRA) ${ }^{[36][37][38]}$. The TRA was unique in its recognition that attitudes (personal factor) and social norms (environmental factor) influence an individual's behavior. On the basis of TRA, Davis, Bagozzi, and Warshaw built a Technology Acceptance model (TAM) that predicted individual receptivity to new technologies ${ }^{[36][37]}$. These studies introduced perceived usefulness and perceived ease of use as additional personal factors to influence individual behavior (in relation to new technologies). In addition to these new personal factors, some researchers have also proposed new environmental factors to predict the adoption of new technologies ${ }^{[39][400][41]}$.

Despite their contributions, these studies have not sufficiently explained the complementary roles of cognition and capabilities in organizations facing technological shifts. Specifically, there remain three unresolved issues. First, there has been no research to explore employee cognitions in response to technology changes. This is a noteworthy oversight, given that employees' cognitions in relation to organizational technologies gradually change and are integrated into the organization's operations ${ }^{[9]}$. Second, there has been no work to evaluate the influence cognitions or capabilities while comparing extant technologies with new ones. Finally, past studies have not considered market properties as moderating forces. Christesen indicated the manner in which new technologies are evaluated varies 
from market to market ${ }^{[42]}$. As such, a consideration of how a specific market influences the effects of cognitions and capabilities is critical.

Based on the above, we use the concept of the product life cycle (PLC) to gauge differences in cognitions related to the technologies. Dean introduced the PLC to suggest different pricing policies for products in different stages of the cycle ${ }^{[43]}$. The PLC is characterized by four stages - product introduction, product growth, product maturity, and product decline - which are determined on the basis of sales trends. Despite its general usefulness, it is difficult to measure the sales of animation technology. Therefore, we gauge where in the PLC an animation technology is by subjectively evaluating its present status in the industry and its future potential for use. We call this method the technology life cycle by subjective evaluation (TLCS). TLCS would dictate that a technology in the introduction stage is expected to gain popularity in the future, but is currently not selling well. In the growth stage, technological advancements would improve the technology's popularity, but its future popularity is in doubt. TLCS indicates that in the maturity stage, the technology's popularity reaches its peak, but its potential for future growth is limited. Finally, in the decline stage, the technology largely disappears from the market and has little to no future potential for growth. TLCS allows us to show the relative positions of the technologies (see Figure 1).

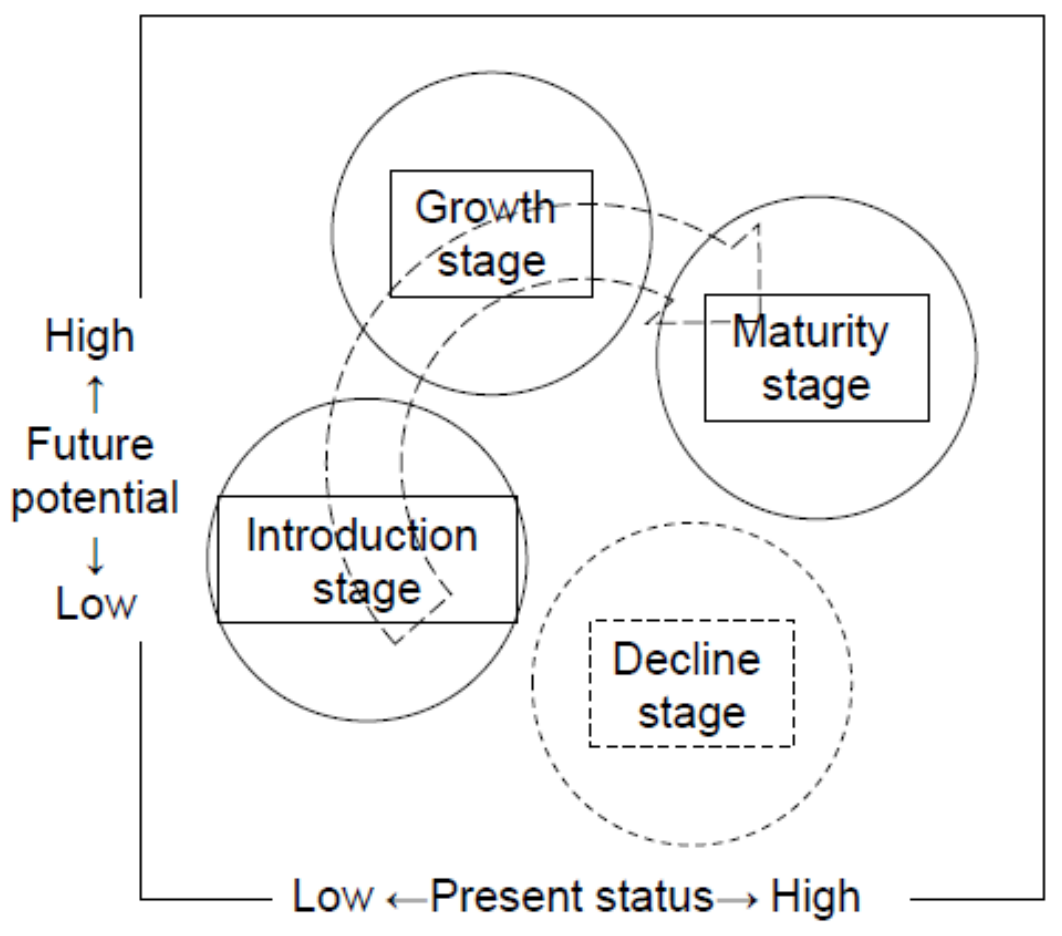

Figure1. Conceptual diagram of TLCS

\section{Methods And Data}

\subsection{Methods}

In this study, we consider how current and future technologies are evaluated (given certain market properties) in the Japanese animation industry. First, to evaluate changes in how technologies are evaluated, we analyze responses provided by animators and animation vocational students. In Japan, many vocational students that study animation go on to work in the animation industry. Therefore, soliciting responses from animation students provides accurate evaluations of technologies that ultimately become obsolete when they reach their careers. It is important to note, however, that we do not collect panel data. Constant progress in technologies means panel data make it difficult to show whether organizational or technological factors influence employee cognitions. For example, if targeting new technology progressed very well, the influence of technological factors would be superior to organizational factors and it would be difficult to interpret the result of panel data. As such, collecting data from two kinds of respondent is appropriate here. 
Second, to gauge relative evaluations for different technologies, we solicit responses in relation to various new technologies in the Japanese animation industry. Specifically, we solicit responses concerning perceptions of freehand drawing, three-dimensional computer graphics (3DCG), hybrid technology (a combination of freehand drawing and 3DCG), Flash animation, and stereovision ${ }^{1}$. For the purposes of our analyses, we consider freehand drawing to be the existing (and baseline) technology. Since origin of animation technology emerged in the early 1800s, a number of animations have been produced with freehand drawing. However, newer technologies allow for more sophisticated practices. 3DCG presents the artist with the subject in three-dimensional space, thereby facilitating three-dimensional art and animation. Although 3DCG originally emerged in the 1960s, it came to be used for works in the early 19th century. For example, Tron (Released in 1982) partly consisted of 3DCG. 3DCG spread more after Pixer's works in 1990s.to the contribution of Pixar animation. In Japan, however, 3DCG has not entirely replaced freehand drawing; each animation technique has its own strengths. Freehand drawing can express any picture and is particularly suited for illustrating human expression. While 3DCG is more suitably for game, uncanny valley remains in the animation industry. For example, While Final Fantasy series have achieved commercial success, Final Fantasy: The Spirits Within( released in 2001) did not. In contrast, hand drawing is not suitable for producing objects that require many lines to express (e.g., ships, planes, robots). If these objects are drawn by hand, it is difficult to maintain consistent quality. However, 3DCG facilitates consistent, quality reproduction. 3DCG is also suitable for expressing the backgrounds of rooms in coordination with camera work and simulation. In contrast, 3DCG is not particularly useful for expressing directional movement coupled with shape-changing. This is much easier (and less costly) produced by hand. Given the complementary strengths of hand drawing and 3DCG, Japanese animation studios often use the techniques in conjunction with one another.

This research analyzes the hybrid technology of 3DCG and the freehand drawing. Flash animation was originally developed by Jonathan Gay of the Future Wave Software company in 1996. Initially called the "Future Splash Animator," the program's name was eventually abbreviated and came to be called Flash. Flash is intended to produce animations to be seen on a website through automatic expressions. Specifically, the computer facilitates animation by appointing the beginning of the action and the actions final state. This simplistic mechanism for animation renders its cost to be lower than freehand drawing, but the quality of Flash animation is inferior to that of freehand drawing. Although Flash technology became popular in China, it has not spread in Japan. Finally, stereovision does not express pictures directly, but instead enables already-established pictures to move in new directions. Stereovision refers differences in depth perception and three-dimensional structures obtained from visual information received by both eyes ${ }^{2}$. it was first exemplified in the 2005 Disney film Chicken Little. Japanese animation studios began to produce films using stereovision around 2010. Because this technology is primarily useful for films that are produced entirely via 3DCG, it has not yet spread too widely.

Third, this project seeks to explore how animation differs in two markets: the television market and the theater market. Specifically, we seek to identify differences in animation techniques used to produce programs on television versus films to be shown in a theater. Television animation series typically takes the form of a 30-minute show to be broadcasted for a season or more. In contrast, animations for films to be shown in theaters are typically more than an hour in length. The most important difference between the production of these two types of animation is quality. Quality demands for theater animations can drive their production costs from hundreds of millions of yen to several billions of yen. For example, the production costs of Studio Ghibli's 1989 film Kiki's Delivery Service totaled about 400 million yen ${ }^{3}$. Production costs for the studio's 1997 film Princess Mononoke was even higher, totaling about 2 billion yen ${ }^{4}$ According to the Ministry of Economy,

\footnotetext{
${ }^{1}$ As for the animation technologies, this study mainly based on Ichikohji(2015) ${ }^{[44]}$.

${ }^{2}$ See Howard and Rogers $(1995)^{[45]}$.

${ }^{3}$ Toshio Suzuki (available from http://www.v-tsushin.jp/search/details/000222/03. html).

${ }^{4}$ Studio Ghibli website (available from http://www.ghibli.jp/30profile/000152. html).
} 
Trade and Industry (2003), production costs for television shows is substantially lower. Producing a 30-minute show costs between 10 million and 12 million yen. Given the higher production costs for animated films to be shown in theaters, it is safe to assume that they are of a superior quality than animations shown in a 30-minute time slot on television.

Based on the above, the present study is designed to evaluate five animation technologies (freehand drawing, 3DCG, hybrid, Flash, stereovision), two markets (theaters and television), and two participant types (animators and vocational college students). We plot these technologies on two evaluative axes to address our research questions. For the purposes of the current study, we developed 20 items that ask about the different variables of interest in all combinations (i.e., 5 technologies $\times 2$ evaluations $\times 2$ markets). For example, one item read "I think that present level of freehand drawing animation is satisfactory for the television animation market". All items were presented as Likert scales ranging from 1 (strongly agree) to 5 (strongly disagree). We performed standard t-tests to compare animators' and vocational students' evaluations, as well as compare the target technologies themselves.

\subsection{Data}

The survey presented to animators was performed as part of a project related to the "human resources excavation and development in the content industry project" commissioned by the Ministry of Economy, Trade and Industry (METI) in 2010. The survey administered to the vocational students was performed during the same period (November to December of 2010). Because of the technological change, this data is too old to reveal the "current" position of the technologies. Therefore, this research cannot explain the recent state of Japanese animation industry. However, this data does not hinder to investigate the cognition of employee. After project members made language adjustments to the questionnaire, it was validated by several business scholars. Following this initial validation, two students and a worker from the animation industry offered a final validation check. Once validated, the questionnaire was distributed to 204 employees of companies that are part of the Japanese Animation Association between December 2010 and February 2011. Of the 204 questionnaires distributed, $153(75 \%)$ were returned), 140 of which had complete data. The questionnaire was also distributed to 342 vocational college students. Of the distributed questionnaires, 302 ( $88 \%$ were returned), 291 of which had complete data.

\section{RESULTS AND DISCUSSION}

Tables 1-1 through 1-4 show the key results of our analyses. These results show that animators tended to evaluate technologies worse than the animation students. In the television market, students' evaluations of the current status of hybrid animation, 3DCG, Flash, and stereovision exceeded those offered by company employees (see Table 1-1). Students also evaluated the future potential of freehand drawing, hybrid animation, and stereovision better than the company employees (see Table 1-2). In the theater market, students evaluated the current status of hybrid animation, 3DCG, Flash, and stereovision significantly better than company employees (see Table 1-3). The student sample also evaluated the future potential of freehand drawing, hybrid animation, Flash, and stereovision as significantly more promising than their employee counterparts (see Table 1-4). There were no significant differences between students and employees with respect to the current status of freehand drawing or the future potential of 3DCG.

Figure 2 illustrates the relationships between the technologies in the Japanese animation industry, as determined by TLCS. Freehand drawing was evaluated most positively in terms of its current status in both the television and theater markets (animators: 3.05 for television, 3.26 for theater; students: 3.21 for television, 3.36 for theater). Hybrid animation was evaluated second-most positively (animators: 2.43 for television, 2.79 for theaters; students: 2.87 for television, 3.13 for theater). Following these consistent evaluations, differences emerged by market. In the television market, Flash was evaluated third-highest (animators: 2.41, students: 2.74) and 3DCG was evaluated fourth-highest (animators: 
The Influence of Work Experience on Subjective Evaluation of Technologies: The Case of the Japanese Animation Industry

2.22, students: 2.67). In the theater market, however, 3DCG was evaluated third-highest (animators: 2.63, students: 2.88) and Flash was evaluated fourth-highest (animators: 2.26, students: 2.67). Stereovision was evaluated worst in both the television and theater markets (animators: 1.96 for television, 2.19 for theater; students: 2.48 for television, 2.64 for theater).

When evaluating the future potential of animation technologies, however, different patterns emerged. Hybrid animation was evaluated most positively in three evaluations (these instances underlined; animators: 3.16 for television, 3.26 for theater; students: 3.47 for television, 3.61 for theater). Animators evaluated 3DCG most positively in the theater market (animators: 3.08 for television, 3.31 for theater; students: 2.97 for television, 3.19 for theater). Freehand drawing was evaluated thirdhighest (animators: 2.45 for television, 2.69 for theater; students: 3.11 for television, 3.45 for theater). Flash was evaluated superior to stereovision in the television market (animators: 2.74 for television, 2.22 for theater; students: 2.76 for television, 2.63 for theater), but stereovision was generally evaluated better in the theater market (animators: 2.45 for television, 2.69 for theater; students: 2.76 for television, 2.63 for theater).

Table1-1. Present status of technologies in the television market

\begin{tabular}{|l|c|c|c|c|c|c|}
\hline & \multicolumn{3}{|c|}{ Students } & \multicolumn{2}{c|}{ Animators } & \\
\hline & mean & S.E. & mean & S.E. & $|\mathrm{t}|$ & p-value \\
\hline Freehand & 3.21 & 0.962 & 3.07 & 1.213 & 1.247 & 0.214 \\
\hline Hybrid & $2.86 * *$ & 0.971 & 2.42 & 1.055 & 4.228 & 0.000 \\
\hline Full 3DCG & $2.67 * *$ & 1.052 & 2.22 & 1.096 & 4.165 & 0.000 \\
\hline Flash & $2.74 * *$ & 0.921 & 2.43 & 1.091 & 2.98 & 0.003 \\
\hline Stereovision & $2.48^{* *}$ & 0.940 & 1.97 & 0.971 & 5.343 & 0.000 \\
\hline
\end{tabular}

$\dagger: p<0.10, *: p<0.05, * *: p<0.01$

Table1-2. Future potential of technologies in the television market

\begin{tabular}{|l|c|c|c|c|c|c|}
\hline & \multicolumn{2}{|c|}{ Students } & \multicolumn{2}{c|}{ Animators } & & \\
\hline & mean & S.E. & mean & S.E. & $|\mathrm{t}|$ & $\mathrm{p}$-value \\
\hline Freehand & $3.13^{* *}$ & 0.987 & 2.68 & 1.030 & 4.415 & 0.000 \\
\hline Hybrid & $3.48^{* *}$ & 0.989 & 3.17 & 1.091 & 2.993 & 0.003 \\
\hline Full 3DCG & 2.98 & 1.078 & 3.09 & 1.056 & 1.009 & 0.313 \\
\hline Flash & 2.76 & 0.952 & 2.74 & 1.047 & 0.257 & 0.797 \\
\hline Stereovision & $2.75^{* *}$ & 1.078 & 2.43 & 0.999 & 2.948 & 0.003 \\
\hline
\end{tabular}

$\dagger: p<0.10, *: p<0.05, * *: p<0.01$

Table1-3. Present status of technologies in the theater market

\begin{tabular}{|c|c|c|c|c|c|c|}
\hline & \multicolumn{2}{|c|}{ Students } & \multicolumn{2}{|c|}{ Animators } & \multirow[b]{2}{*}{$|\mathrm{t}|$} & \multirow[b]{2}{*}{ p-value } \\
\hline & mean & S.E. & mean & S.E. & & \\
\hline Freehand & 3.35 & 0.967 & 3.26 & 1.121 & 0.819 & 0.413 \\
\hline Hybrid & $3.12 * *$ & 0.961 & 2.79 & 1.057 & 3.188 & 0.002 \\
\hline Full 3DCG & $2.87 *$ & 0.988 & 2.64 & 1.106 & 2.135 & 0.034 \\
\hline Flash & $2.67 * *$ & 0.869 & 2.27 & 1.021 & 4.062 & 0.000 \\
\hline Stereovision & $2.64 * *$ & 0.892 & 2.19 & 0.987 & 4.645 & 0.000 \\
\hline
\end{tabular}

$\digamma: p<0.10, *: p<0.05, * *: p<0.01$

Table1-4. Future potential of technologies in the theater market

\begin{tabular}{|l|c|r|r|r|r|r|}
\hline & \multicolumn{2}{|c|}{ Student } & \multicolumn{2}{c|}{ Animator } & & \\
\hline & mean & S.E. & mean & S.E. & $|\mathrm{t}|$ & $\mathrm{p}$-value \\
\hline Freehand & $3.46^{* *}$ & 0.967 & 3.05 & 1.066 & 4.101 & 0.000 \\
\hline Hybrid & $3.61^{* *}$ & 0.961 & 3.28 & 1.044 & 3.298 & 0.001 \\
\hline Full 3DCG & 3.20 & 0.988 & 3.32 & 1.049 & 1.027 & 0.305 \\
\hline Flash & $2.63^{* *}$ & 0.869 & 2.19 & 0.949 & 4.498 & 0.000 \\
\hline Stereovision & $2.95^{* *}$ & 0.892 & 2.67 & 1.089 & 2.595 & 0.010 \\
\hline
\end{tabular}

$\dagger: p<0.10, *: p<0.05, * *: p<0.01$ 


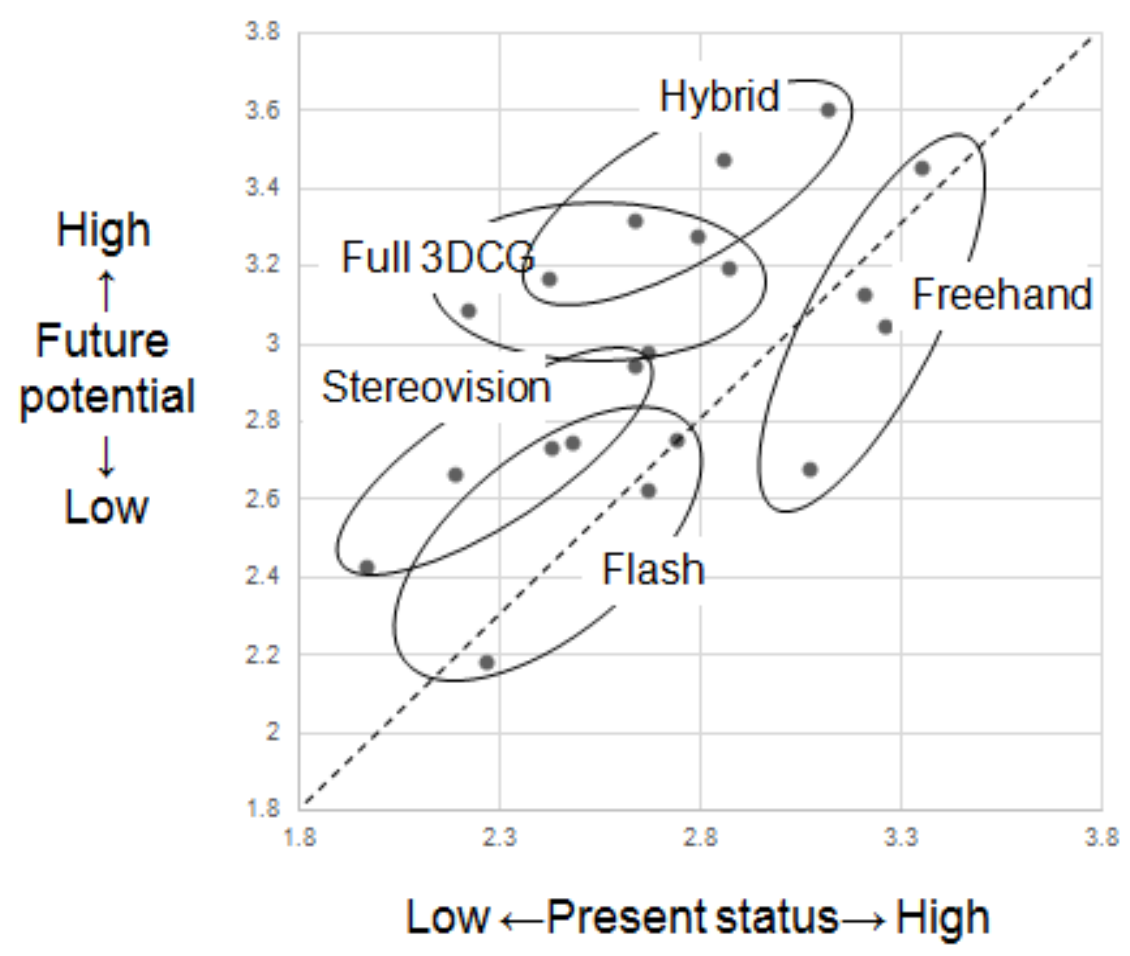

Figure2. TLCS comparison of technologies in the Japanese animation industry

The purpose of this study was to explore how employees' cognitions change in response to the introduction and use of new technologies. Our analyses revealed several important findings by comparing the cognitions of animators who have already worked in the industry to those of vocational animation students. First, we found that employees negatively evaluate technologies mostly. The experience working for the industry have employees recognize the faults of technologies. Second, however, how experience affects partly depends on what technology is and how to evaluate. While the experience negatively affects the future potential of existing technologies and the present status of promising new technologies, it does not affect the present status of existing ones and the future potential of promising ones (Table 2).

Table2. How the experience affects evaluation of technologies

\begin{tabular}{|l|l|l|}
\hline & Present status & Future potential \\
\hline Established existing technologies & Not affect & Negatively affect \\
\hline Promising new technologies. & Negatively affect & Not affect \\
\hline
\end{tabular}

TLCS allowed us to subjectively evaluate each of the technologies of interest in 2010 as follows. Freehand drawing is an existing technology in its maturity stage of the life cycle. Its current status is at its peak and exceeds its future potential. Both 3DCG and hybrid technology (which integrates hand drawing and 3DCG) are in the growth stage of the life cycle; their present states are similar to freehand drawing, but their future potential exceeds their current status. Flash is in the introduction stage, because there are no significant differences between its current status and future potential (both are low). Finally, stereovision is also in its introduction stage because its current usage is relatively limited, but its future potential for growth is strong. It is important to note, however, that stereovision was more positively evaluated for use in the theater market than the television market.

\section{Limitations AND FUTURE RESEARCH}

This study analyzed employee's subjective evaluation affecting cognition and capabilities of organization for technological shift. However, some problems remain. First, although there is no problem in the analysis, data of this research is old. In the future study, it is necessary to reconfirm about the validity be the comparison with new data and panel data. Second, TLCS need baseline technology to decide the life stage of target technologies as it shows the relative position of technologies. Therefore, it is necessary for future studies to accumulate the evaluation of many technologies in the several industries. 


\section{ACKNOWLEDGEMENT}

This research was supported by JSPS KAKENHI Grant number JP16K21406

\section{REFERENCES}

[1] Wernerfelt, B. (1984). A resource - based view of the firm. Strategic Management Journal, 5(2), 171-180.

[2] Prahalad, C. K. and Hamel, G. (1990). The Core Competence of the Corporation. Harvard Business Review, 68(3), 79-91.

[3] Leonard - Barton, D. (1992). Core capabilities and core rigidities: A paradox in managing new product development. Strategic Management Journal, 13(S1), 111-125.

[4] Levitt, B., and March, J. G. (1988). Organizational learning. Annual Review of Sociology, 14(1), 319-338.

[5] Lieberman, M. B., and Montgomery, D. B. (1988). First - mover advantages. Strategic Management Journal, 9(S1), 41-58.

[6] Vergne, J. P., and Depeyre, C. (2016). How do firms adapt? A fuzzy-set analysis of the role of cognition and capabilities in US defense firms' responses to 9/11. Academy of Management Journal, 59(5), 16531680.

[7] Weick, K. E. (1979). Cognitive processes in organizations. Research in Organizational Behavior, 1(1), 4174.

[8] Weick, K. E. (1990). Technology as equivoque: sensemaking in new technologies. In P. S. Goodman \& L. S. Sproull. The Jossey- Bass management series. Technology and organizations. Jossey-Bass, San Francisco.

[9] Garud, R., and Rappa, M. A. (1994). A socio-cognitive model of technology evolution: The case of cochlear implants. Organization Science, 5(3), 344-362.

[10] Benner, M. J., and Tripsas, M. (2012). The influence of prior industry affiliation on framing in nascent industries: the evolution of digital cameras. Strategic Management Journal, 33(3), 277-302.

[11] Danneels, E. (2011). Trying to become a different type of company: Dynamic capability at Smith Corona. Strategic Management Journal, 32(1), 1-31.

[12] Eggers, J. P., and Kaplan, S. (2013). Cognition and capabilities: A multi-level perspective. The Academy of Management Annals, 7(1), 295-340.

[13] Gavetti, G. (2005). Cognition and hierarchy: Rethinking the microfoundations of capabilities' development. Organization Science, 16(6), 599-617.

[14] Helfat, C. E., and Peteraf, M. A. (2015). Managerial cognitive capabilities and the microfoundations of dynamic capabilities. Strategic Management Journal, 36(6), 831-850.

[15] Kunc, M. H., and Morecroft, J. D. (2010). Managerial decision making and firm performance under a resource - based paradigm. Strategic Management Journal, 31(11), 1164-1182.

[16] Rosenbloom, R. S. (2000). Leadership, capabilities, and technological change: The transformation of NCR in the electronic era. Strategic Management Journal, 21(10/11), 1083-1103.

[17] Tripsas, M., and Gavetti, G. (2000). Capabilities, cognition, and inertia: Evidence from digital imaging. Strategic Management Journal, 21(10/11), 1147-1161.

[18] Abernathy, W. J., and Clark, K. B. (1985). Innovation: Mapping the winds of creative destruction. Research policy, 14(1), 3-22.

[19] Anderson, P., and Tushman, M. L. (1990). Technological discontinuities and dominant designs: A cyclical model of technological change. Administrative Science Quarterly, 35(4), 604-633.

[20] Henderson, R. M., and Clark, K. B. (1990). Architectural innovation: The reconfiguration of existing product technologies and the failure of established firms. Administrative Science Quarterly, 35(1) 9-30.

[21] Mitchell, W. (1989). Whether and when? Probability and timing of incumbents' entry into emerging industrial subfields. Administrative Science Quarterly, 34(2), 208-230.

[22] Tripsas, M. (1997). Unraveling the process of creative destruction: Complementary assets and incumbent survival in the typesetter industry. Strategic Management Journal, 18(S1), 119-142.

[23] Tushman, M. L., and Anderson, P. (1986). Technological discontinuities and organizational environments. Administrative Science Quarterly, 31(3), 439-465.

[24] Eisenhardt, K. M., and Martin, J. A. (2000). Dynamic capabilities: what are they?. Strategic Management Journal, 21(10/11), 1105-1121. 
[25] Helfat, C. E., and Winter, S. G. (2011). Untangling dynamic and operational capabilities: Strategy for the (N) ever - changing world. Strategic Management Journal, 32(11), 1243-1250.

[26] Teece, D. J., Pisano, G., and Shuen, A. (1997). Dynamic capabilities and strategic management. Strategic Management journal, 18(7), 509-533.

[27] Zollo, M., and Winter, S. G. (2002). Deliberate learning and the evolution of dynamic capabilities. Organization science, 13(3), 339-351.

[28] Adner, R., and Helfat, C. E. (2003). Corporate effects and dynamic managerial capabilities. Strategic Management Journal, 24(10), 1011-1025.

[29] Kor, Y. Y., and Mesko, A. (2013). Dynamic managerial capabilities: Configuration and orchestration of top executives' capabilities and the firm's dominant logic. Strategic Management Journal, 34(2), 233-244.

[30] Moliterno, T. P., and Wiersema, M. F. (2007). Firm performance, rent appropriation, and the strategic resource divestment capability. Strategic Management Journal, 28(11), 1065-1087.

[31] Peteraf, M., and Reed, R. (2007). Managerial discretion and internal alignment under regulatory constraints and change. Strategic Management Journal, 28(11), 1089-1112.

[32] Salvato, C. (2009). Capabilities unveiled: The role of ordinary activities in the evolution of product development processes. Organization Science, 20(2), 384-409.

[33] Sirmon, D. G., and Hitt, M. A. (2009). Contingencies within dynamic managerial capabilities: interdependent effects of resource investment and deployment on firm performance. Strategic Management Journal, 30(13), 1375-1394.

[34] Laamanen, T., and Wallin, J. (2009). Cognitive dynamics of capability development paths. Journal of Management Studies, 46(6), 950-981.

[35] Kaplan, S. (2008). Cognition, capabilities, and incentives: Assessing firm response to the fiber-optic revolution. Academy of Management Journal, 51(4), 672-695.

[36] Davis, F. D. (1989). Perceived usefulness, perceived ease of use, and user acceptance of information technology. MIS quarterly, 13(3), 319-340.

[37] Davis, F. D., Bagozzi, R. P., and Warshaw, P. R. (1989). User acceptance of computer technology: a comparison of two theoretical models. Management Science, 35(8), 982-1003.

[38] Fishbein, M., and Ajzen, I. (1975). Belief, attitude, intention, and behavior: An introduction to theory and research Addison-Wesley, Boston.

[39] Compeau, D. R., and Higgins, C. A. (1995). Computer self-efficacy: Development of a measure and initial test. MIS quarterly, 19(2), 189-211.

[40] Taylor, S., and Todd, P. A. (1995). Understanding information technology usage: A test of competing models. Information Systems Research, 6(2), 144-176.

[41] Venkatesh, V., Morris, M. G., Davis, G. B., and Davis, F. D. (2003). User acceptance of information technology: Toward a unified view. MIS quarterly, 27(3), 425-478.

[42] Christenson, C. (1997). The innovator's dilemma. Harvard Business School Press, Cambridge.

[43] Dean, J. (1950). Pricing policies for new products. Harvard University Press, Cambridge.

[44] Ichikohji, T. (2015). Hybrid seihin no kaihatsu no management - Shin gijutu to kizon kijutu no tougou senryaku (Doctral dissertation). University of Tokyo, Tokyo. Japan. (in Japanese)

[45] Howard, I. P., and Rogers, B. J. (1995). Binocular vision and stereopsis. Oxford University Press, Oxford.

\section{AUTHOR'S BIOGRAPHY}

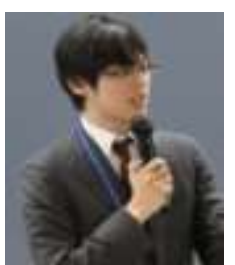

Takeyasu Ichikohji, is an Associate Professor in the Department of Business Administration at Toyo University. He took his Ph.D. in Economics from the University of Tokyo. He studies about the following subjects and fields: Innovation Management, Consumer Behavior, and Japanese Entertainment Industries such as Animation, Game and Sports.

Citation: Takeyasu, Ichikohji. "The Influence of Work Experience on Subjective Evaluation of Technologies: The Case of the Japanese Animation Industry." International Journal of Managerial Studies and Research (IJMSR), vol 5, no. 11, 2017, pp. 8-16. doi:http://dx.doi.org/10.20431/2349-0349.0511002.

Copyright: (C) 2017 Authors. This is an open-access article distributed under the terms of the Creative Commons Attribution License, which permits unrestricted use, distribution, and reproduction in any medium, provided the original author and source are credited. 